\title{
Effectiveness of dexamethasone or adrenaline with lignocaine $2 \%$ for prolonging inferior alveolar nerve block: a randomized controlled trial
}

\author{
Saroj Prasad Deo ${ }^{1}$, Md Shakeel Ahmad ${ }^{2}$, Abanish Singh ${ }^{3}$ \\ ${ }^{1}$ Department of Oral and Maxillofacial Surgery, ${ }^{2}$ Department of Dentistry, National Medical College, \\ ${ }^{3}$ Department of Community Dentistry, MB Kedia Dental College, Birgunj, Nepal
}

\begin{abstract}
J Korean Assoc Oral Maxillofac Surg 2022;48:21-32)
Objectives: Inferior alveolar nerve block (IANB) is commonly used for mandibular dentoalveolar surgery. The objective of this study was to evaluate and compare the effectiveness of coadministration of dexamethasone $(4 \mathrm{mg} / \mathrm{mL})$ or adrenaline $(0.01 \mathrm{mg} / \mathrm{mL})$ as an adjuvant with lignocaine $2 \%$ in IANB during third molar surgery (TMS).

Patients and Methods: This double-blind, randomized controlled trial was conducted between March and August 2020. The investigators screened patients needing elective TMS under local anesthesia. Based on strict inclusion and exclusion criteria, patients were enrolled in this study. These patients were assigned randomly into two study groups: dexamethasone group (DXN) or adrenaline group (ADN). Outcome variables were postoperative edema, trismus, visual analogue scale (VAS), perioperative analgesia, onset time, and duration of IANB.

Results: Eighty-three patients were enrolled in this study, of whom 23 (27.7\%) were eliminated or excluded during follow-up. This study thus included data from 60 samples. Mean age was 32.28 \pm 11.74 years, including 28 females (46.7\%) in the ADN (16 patients, 57.1\%) and DXN (12 patients, 42.9\%) groups. The duration of action for DXN (mean \pm standard deviation [SD], 4:02:07 $\pm 0: 34: 01$ hours; standard error [SE], 0:06:00 hours; log-rank $P=0.001$ ) and for $\mathrm{ADN}$ (mean $\pm \mathrm{SD}, 1: 58: 34 \pm 0: 24: 52$ hours; $\mathrm{SE}, 0: 04: 42$ hours; log-rank $P=0.001$ ) were found. Similarly, time at which 1st analgesic consume and total number of nonsteroidal antiinflammatory drugs need to rescue postoperative analgesia was found statistically significant between study groups $(t$ $(58)=11.95$; confidence interval, $-2: 25: 41$ to $-1: 43: 53 ; P=0.001)$. Early-hours VAS was also significantly different between the study groups.

Conclusion: A single injection of dexamethasone prolongs the duration of action of lignocaine $2 \%$ IANB. Additionally, it can be used in cases where adrenaline is contraindicated.
\end{abstract}

Key words: Dexamethasone, Inferior alveolar nerve, Nerve block, Lidocaine, Third molar

[paper submitted 2021. 7. 29 / revised 2021. 9. 18 / accepted 2021. 9. 27]

\section{Introduction}

Pain is an important issue for surgical patients, and perioperative pain management is an integral part of patient care in modern surgical practices. Halsted and Hall, 1884 discovered the first successful nerve block, i.e., inferior alveolar nerve block (IANB) ${ }^{1}$. This discovery revolutionized surgical specialties worldwide, dramatically improving patient care and permitting the progression of many sophisticated surgical

\section{Saroj Prasad Deo}

Department of Oral and Maxillofacial Surgery, National Medical College, P.O. Box No. 78, Birgunj 44500, Nepal

TEL: $+977-9845454168$

E-mail:drsrjdeo@gmail.com

ORCID: https://orcid.org/0000-0001-5286-2065

(c) This is an open-access article distributed under the terms of the Creative Commons Attribution Non-Commercial License (http://creativecommons.org/ licenses/by-nc/4.0/), which permits unrestricted non-commercial use, distribution, and reproduction in any medium, provided the original work is properly cited.

Copyright (C) 2022 The Korean Association of Oral and Maxillofacial Surgeons. procedures $^{2}$. The local anaesthetic agents (LAa) have become ideal therapeutic drugs for ambulatory surgery because they do not require sophisticated logistics and ensure that patients are comfortable enough to be discharged home immediately, resulting in reduction of the overall cost of surgery ${ }^{3}$. Although intraoperative pain is managed with anaesthesia, postoperative pain can be a serious issue for surgical patients ${ }^{4,5}$. Previous studies found that approximately $30 \%$ to $75 \%$ of patients experienced moderate to severe pain postoperatively ${ }^{6-8}$. Effective pain management has been recognized as an essential indicator for health care quality, surgical outcomes, and patient satisfaction. An ample number of studies found that most patients ranked clinicians based on postoperative pain as their most profound concern, highlighting the necessity for prolonged postoperative analgesia ${ }^{6-8}$.

Every year, millions of people undergo third molar surgery (TMS) and experience postoperative pain at various levels, 
i.e., moderate to severe in intensity ${ }^{9-11}$. TMS has become the model most frequently used for postoperative acute pain studies. Sufficient numbers of patients available for sample sizes of this particular type of study have attracted researcher attention for clinical trails ${ }^{12}$. Local anesthetic (LA) blocks with long-acting LAa were successful for management of perioperative pain after surgery. Unfortunately, narrow therapeutic margins and higher cardiotoxicity were reported. Therefore, clinicians have been searching for new and safer drugs to manage perioperative pain ${ }^{13-15}$. Adjuvant drugs have been most commonly investigated with local anaesthesia ${ }^{16-23}$. Initially, limited only to the fields of anaesthesiology and orthopaedic surgery, dentistry has resulted in an effort to increase sensory nerve block duration with short lived LAa. Epinephrine has been used most extensively in this capacity $^{17}$, while taking its relatively limited efficacy and cautious use into consideration. The most commonly used adjuvant drugs are dexamethasone ${ }^{18,24-30}, \alpha_{2}$ agonists (i.e., clonidine and dexmedetomidine $)^{19,20}$, opioids (i.e., buprenorphine) $)^{29}$, ketamine $^{24}$, midazolam ${ }^{25}$, hyaluronidase ${ }^{26}$, and neostigmine ${ }^{27}$. Dexamethasone has been frequently used as an adjuvant for various nerve blocks, i.e., brachial plexus, femoral, intercostal, and axillary nerve blocks, during limb surgery ${ }^{27-33}$, but the exact mechanism of prolonged nerve blocks remains unclear. However, the adjuvant use of dexamethasone was not studied with IANB.

The present study was designed to search for better quality perioperative analgesics with a single injection of co-admix dexamethasone and lignocaine in IANB during TMS. The purpose of the present study was to compare the efficacy of two adjuvant drugs, i.e., adrenaline and dexamethasone with lignocaine $2 \%$ in IANB, and their effect on postoperative sequelae after TMS. The objective was to compare the effectiveness of coadministration of dexamethasone $(4 \mathrm{mg} / \mathrm{mL})$ or adrenaline $(0.01 \mathrm{mg} / \mathrm{mL})$ with lignocaine $2 \%$ in IANB during TMS. Additionally, this study tested the null hypothesis that the adjuvant drugs, dexamethasone and adrenaline, exhibited equal effects in prolonging IANB with lignocaine $2 \%$ during TMS. To the best of our knowledge, no study has compared the efficacy of a freshly prepared mixture of lidocaine with adrenaline to that of lignocaine with dexamethasone.

\section{Patients and Methods}

\section{Study design}

The researchers conducted a prospective, double-blind, randomized controlled trial. Written informed consent was obtained from all the study participants. The possible risks and benefits of the procedure were described to all the patients. Subjects willing to participate in the study were scheduled for TMS in the morning. Ethical approval was obtained from the institutional review committee, and trial registration was performed on clinicaltrail.gov (No. NCT04850885).

\section{Study setting and population}

This quantitative experimental study was conducted in the Department of Oral and Maxillofacial Surgery, National Medical College, Birgunj from March 2020 to August 2020. The study subjects were American Society of Anaesthesiologists (ASA) I-II patients presenting for elective TMS under inferior alveolar block local anaesthesia. The sample size calculation was performed using the formula $2 \mathrm{SD}^{2}(\mathrm{Za} / 2+\mathrm{Z} \beta)^{2} /$ $\mathrm{d}^{2}$, where SD (standard deviation from the previous study), $\mathrm{Za} / 2$ (standard normal variance to the level of significance [1\% type I error, $P<0.01$ was 2.58$]),(Z \beta=$ standard normal variance for power [for $90 \%$ power was 1.28 ]), $\mathrm{d}$ (effect size [the difference between the mean value of the previous study] $)^{27-34}$. The participants were randomly assigned into two groups: 1st, dexamethasone group (DXN) and 2nd, adrenaline group (ADN).

\section{Selection criteria}

Inclusion criteria were patients above age 18 who required oral surgery under local anaesthesia and could understand and were willing to participate in the study. Non-inclusion criteria were contraindications to dexamethasone (i.e., peptic ulcer, renal insufficiency, pregnancy, or lactating females), allergy to drugs used in this study (lignocaine, dexamethasone, Amoxycillin, or piroxicam), aged younger than 18 years or older than 85 years, ASA physical status >III, TMS needing to be performed under general anaesthesia, patients with any condition precluding the limitation of intraoperative trial drug (lignocaine, adrenaline) administration (i.e., significant coronary artery disease, congestive heart failure), or those receiving any pre-medications (including nonsteroidal antiinflammatory drugs [NSAIDs], opioids, benzodiazepines, and clonidine, antibiotics, or anti-inflammatory drugs) within two weeks of study entry. In addition, radiographs showing high and bifid mandibular foramen were not included. Exclusion criteria involved subjects who had to consume analgesic drugs other than piroxicam $20 \mathrm{mg}$, those whose numbness of 
the tongue and lip was not achieved up to 15 minutes after injection (failure of a block), and subjects who did not respond on the visual analogue scale (VAS) and did not come for second and seventh postoperative follow-ups.

\section{Study variables}

Predictor variables were socio-demographic, LA administration time, surgery start time, surgery end time, and operative time. Outcome variables were oedema, trismus, perception of pain in VAS, postoperative analgesia, onset time, and duration of action. The confounding variables were stress and anxiety of the subjects, type and degree of difficulty of the operative procedure, and experience of the surgeon. A single experienced surgeon performed all the surgical procedures following standard operative protocols, allowing for fixed confounding variables.

\section{Drug preparation}

This study used a freshly prepared mixture of adrenaline or dexamethasone with lignocaine for the groups. The $9 \mathrm{~mL}$ solution was discarded, and the remaining $1 \mathrm{~mL}$ solution was diluted with $9 \mathrm{~mL}$ normal saline (NS). This freshly prepared homogenous mixture contained adrenaline $(0.01 \mathrm{mg} / \mathrm{mL})$. From this solution, only $2 \mathrm{~mL}$ of solution was transferred to a $5 \mathrm{~mL}$ syringe, and $2 \mathrm{~mL}$ of lignocaine $(20 \mathrm{mg} / \mathrm{mL})$ was added to the same syringe marked as mixture A. Similarly, for Group DXN, $2 \mathrm{~mL}$ of dexamethasone ( $4 \mathrm{mg} / \mathrm{mL}$ ) was withdrawn in an identical $5 \mathrm{~mL}$ syringe, and $2 \mathrm{~mL}$ of lignocaine $(20 \mathrm{mg} / \mathrm{mL})$ was added to create mixture B.

\section{Allocation and randomization of subjects}

The non-probability convenience sampling method was used to select the subjects for this study based on availability and willingness to take part. The details of patient recruitment, and flow-ups in this study are shown in Fig. 1. Seventy-three subjects were assigned randomly into one of two groups: DXN or ADN. Group ADN had received $4 \mathrm{~mL}$ of mixture A, whereas Group DXN received $4 \mathrm{~mL}$ of mixture $\mathrm{B}$. Stratified randomization was performed in a permuted technique. Therefore, each subject would be assigned on a firstcome, first basis.

\section{Blinding process}

Blinding of this clinical study was performed by confi-

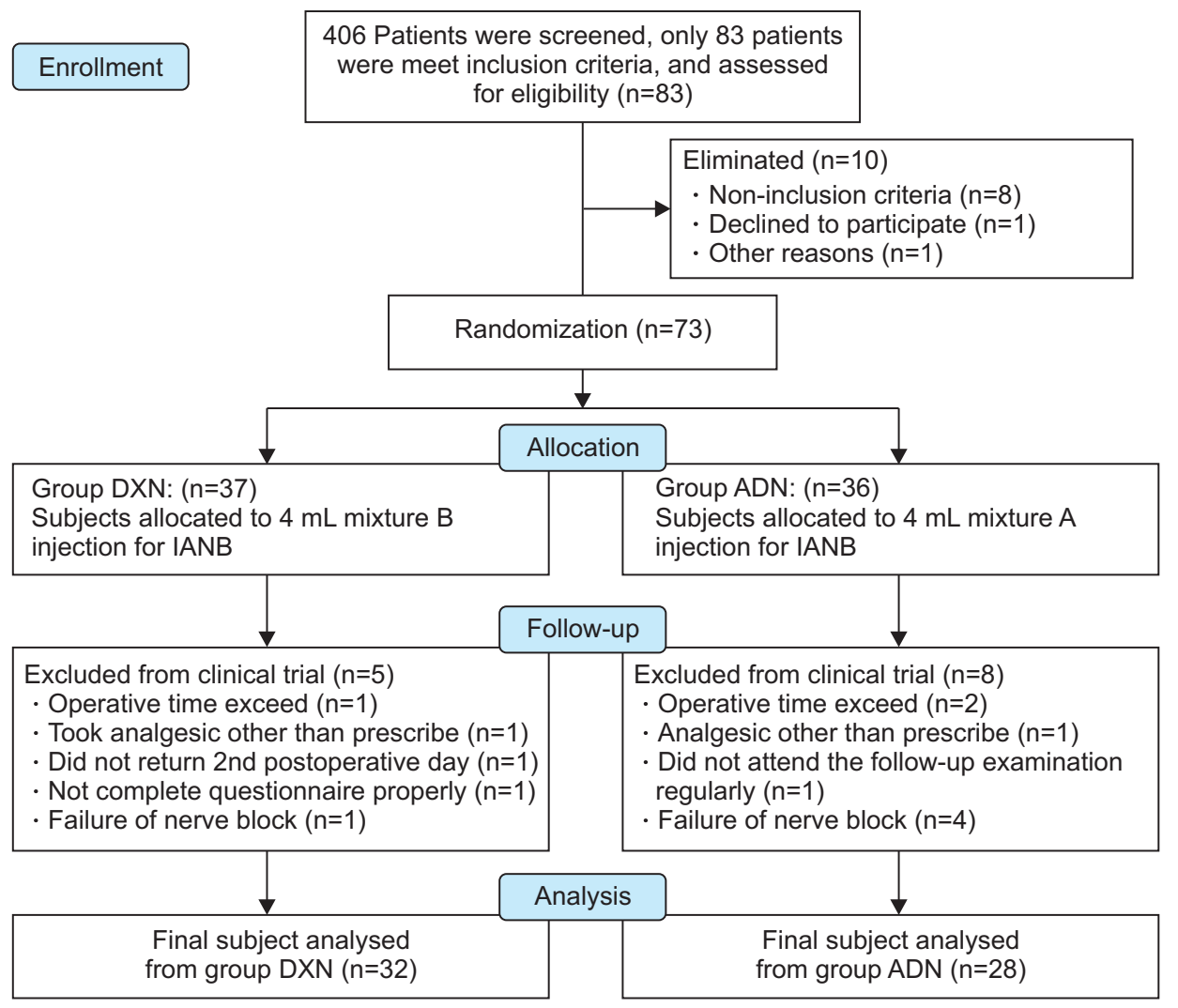

Fig. 1. CONSORT (Consolidated Standards of Reporting Trials) diagram; flow chart detailing patient's recruitment and flow-up in this study. (DXN: dexamethasone, IANB: inferior alveolar nerve block, ADN: adrenaline) Saroj Prasad Deo et al: Effectiveness of dexamethasone or adrenaline with lignocaine $2 \%$ for prolonging inferior alveolar nerve block: a randomized controlled trial. J Korean Assoc Oral Maxillofac Surg 2022 
dential support staff hired for documentation and blinding. Details of the role and responsibilities were described to him/ her. The study materials, i.e., $30 \mathrm{~mL}$ vial of lignocaine $2 \%$ (20 mg/mL xylocaine; AstraZeneca, Bengaluru, India); $2 \mathrm{~mL}$ of Inj. dexamethasone (4 mg/mL Inj., Dexona; Zydus Alidac, Ahmedabad, India), adrenaline $1 \mathrm{mg} / \mathrm{mL}$ (Actiza, Surat, India), NS, and an identical $5 \mathrm{~mL}$ syringe and file were provided to supporting staff. On the day of surgery, drugs were prepared for IANB - either $4 \mathrm{~mL}$ of mixture B or $4 \mathrm{~mL}$ of mixture A (freshly prepared) in $5 \mathrm{~mL}$ identical syringes as described in drug preparation. The patient's name and age were documented in a file, and a unique code was generated and labelled on the syringes. The operator received a loaded syringe containing $4 \mathrm{~mL}$ of clear solution $\mathrm{X}$ of either mixture $\mathrm{A}$ or B with a unique code. The special code was copied to Performa during data collection. Both the operator and patient were blinded. The operator used the same syringe containing clear solution $\mathrm{X}$ for IANB in the same site of surgery.

\section{Procedures}

The modified IANB technique was used to block the inferior alveolar nerve (IAN) as described by Clark and Homes (1959). The high success rate was the reason to choose this technique. The patients were requested to keep their mouths wide open with their occlusal plane parallel to the floor. Palpation of the anatomical landmarks was correctly performed, and the guide finger was positioned at the retromolar fossa. A $5 \mathrm{~mL}$ syringe equipped with a 24-gauge needle with a length of $3.6 \mathrm{~cm}$ was used. The needle was advanced into the tissue just above the fingernail until bone was contacted. The body of the syringe was redirected over the lower central incisors and maintained parallel to the molars in the horizontal plane at the same time. The needle was inserted another $2 \mathrm{~cm}$ into the tissue, and $3.5 \mathrm{~mL}$ of solution $\mathrm{X}$ was deposited $1 \mathrm{~cm}$ higher than usual after multiple aspirations $\left(90^{\circ}\right.$ two planes). Furthermore, $1 \mathrm{~mL}$ of solution $\mathrm{X}$ was deposited after the needle was withdrawn into the pterygomandibular space. Pre, intra, and postoperative vitals were monitored. Anaesthetic assessments (subjective and objective) were performed as described below. After profound anaesthesia was achieved, the same surgeon performed standard surgical procedures for the third molars. The duration of the operation was recorded as the period between the initial incision to the last suture placed. Details of each procedure were recorded. After completing the surgical procedure, the patients were shifted to the postoperative ward for the next 6 hours for observation and further data collection. Postoperative instructions were provided to all the patients. Amoxicillin $500 \mathrm{mg}$ (Cap. Wymox 500; Pfizer, Mumbai, India) was prescribed to the patients orally three times a day for five days and piroxicam $20 \mathrm{mg}$ (Fc-tab Dolonex DT; Pfizer) orally as required for "rescue" analgesia. They were provided a VAS (no pain, 0-1; mild pain, 2-3; moderate pain, 4-5; severe pain, 6-7; very severe pain, 8-9) and were instructed about the rating scale. The patients were asked to report to the outpatient setting on the second and seventh postoperative days to observe the surgical outcomes and report any adverse drug effects.

\section{Outcome measurements}

Surgical outcomes of postoperative facial swelling, trismus, and duration of analgesia and adverse drug reactions of nausea/vomiting, bruise, paraesthesia of the lip and tongue, slow wound healing, mood changes, wound infection, and hyperglycaemia were recorded during the follow-ups in the outpatient's department. Standard and valid tools were used for data collection with the Performa and $10 \mathrm{~cm}$ VAS. These tools are reliable and valid and have been increasingly used to evaluate patients' pain perception. The armamentarium used for this study included a pulse oximeter $\left(\mathrm{SpO}_{2}\right)$, thermometer, sphygmomanometer, and stopwatch. Support staff were provided all the above armamentarium and informed on test preparation or control group drugs according to the permuted random table. The staff recorded preoperative, intraoperative, and postoperative data. Pre, intra, and postoperative vitals with non-invasive blood pressure and the respiratory rate were recorded with a pulse $\mathrm{SpO}_{2}$, allowing for assessment of any adverse effects of the drugs. Wound healing and other local tissue reactions were recorded in the second and seventh postoperative days. IANB was assessed subjectively and objectively. The patients were frequently questioned regarding the numbness of the lip and tongue a few seconds after the administration of the test drugs. Simultaneously, the patients were instructed to palpate the lips and compare sensation or numbness in the upper and lower lips. They were asked to report when lower lip numbness had occurred. Furthermore, the nerve block was assessed objectively by pricking the buccal and lingual gingiva in the canine and first molar areas with a blunt instrument. The block's success was standardized for profound lip numbness for all the patients. When profound lip numbness was not recorded after 15 minutes, the IANB was considered a failure, and these patients were eliminated from the study. 
In the postoperative ward, vitals were recorded for up to 6 postoperative hours. The subjects were instructed to palpate the lower lip and tongue every 20 minutes to determine numbness (no feeling) until normal sensation was regained and asked to note the time. All the events were recorded. The patients were instructed to first consume NSAIDs for postoperative rescue analgesia when moderate pain started and to document the time. The subjects were instructed not to take any other trail analgesic drugs, i.e., piroxicam $20 \mathrm{mg}$ (Fc-tab Dolonex DT; Pfizer).

\section{Statistical analyses}

Data analysis was performed using IBM SPSS Statistics software (ver. 11.5; IBM, Armonk, NY, USA). Independent Student's $t$-test analyses were performed to test the hypothesis, group statistics, and provide a comparison between the

Table 1. Demographic distribution in both study groups

\begin{tabular}{lcccc}
\hline Characteristic & $\begin{array}{c}\text { Overall } \\
(\mathrm{n}=60)\end{array}$ & $\begin{array}{c}\text { Group ADN } \\
(\mathrm{n}=28)\end{array}$ & $\begin{array}{c}\text { Group DXN } \\
(\mathrm{n}=32)\end{array}$ & $P$-value \\
\hline Age $(\mathrm{yr})$ & $32.28 \pm 11.74$ & $33.82 \pm 11.03$ & $30.94 \pm 12.35$ & 0.915 \\
Sex & & & & \\
$\quad$ Male & $32(53.3)$ & $12(42.9)$ & $20(62.5)$ & 0.195 \\
Female & $28(46.7)$ & $16(57.1)$ & $12(37.5)$ & \\
\hline
\end{tabular}

(ADN: adrenaline, DXN: dexamethasone)

$* P \leq 0.05$ is statistically significant.

Values are presented as mean \pm standard deviation or number (\%). Saroj Prasad Deo et al: Effectiveness of dexamethasone or adrenaline with lignocaine $2 \%$ for prolonging inferior alveolar nerve block: a randomized controlled trial. J Korean Assoc Oral Maxillofac Surg 2022 groups. Descriptive analysis was performed by calculating the frequency and percentages for categorical data. The mean and standard deviation were calculated for continuous data. The Pearson chi-square test and the $t$-test were applied to determine the association between the groups. The confidence level was set at $95 \%$. The significance level was set at $P<0.05$.

\section{Results}

The finding of this study was generated from 60 subjects from both study groups. Fig. 1 is a flow chart that describes the final subjects enrolled in this study. The failure rate of IANB was $2.7 \%$ in DXN and $11.11 \%$ in ADN.(Fig. 1) The mean and standard deviation of the predictor variables were statistically similar in the two groups.(Table 1,2 )

\section{Analgesic outcomes}

The duration of action (IANB) was longer in DXN (4:02:07 $\pm 0: 34: 01$ hours) compared to $\mathrm{ADN}(1: 58: 34 \pm 0: 24: 52$ hours) $(\mathrm{t}(58)=-15.85 ; P=0.001)$, whereas the latency periods were similar in DXN (0:04:09 $\pm 0: 02: 27$ hours) and ADN (0:04:21 $\pm 0: 02: 13$ hours) ( $(58)=0.330 ; 95 \%$ confidence interval $[\mathrm{CI}],-0: 01: 01$ to $0: 01: 25 ; P=0.742$ ).(Table 2 ) Table 3 shows the assessment onset time and duration of action (IANB). The onset time was found in increasing order at different regions, i.e., molar $<$ canine $<$ tongue $<$ lip.(Fig. 2. A) However, the duration of nerve blocks was found in decreas-

Table 2. Comparison duration of perioperative analgesia in different time intervals between the dexamethasone and adrenaline groups

\begin{tabular}{|c|c|c|c|c|c|c|}
\hline Characteristic & Overall & Group ADN & Group DXN & t-value & 95\% CI (hr:min:s) & $P$-value \\
\hline $\begin{array}{l}\text { Time of administration } \\
\text { of LA in } 24 \text { hours [A] }\end{array}$ & $10: 25: 01 \pm 0: 36: 32$ & $10: 24: 21 \pm 0: 33: 39$ & $10: 25: 36 \pm 0: 39: 24$ & $\mathrm{t}(58)=-0.130$ & $-0: 20: 19$ to $0: 17: 50$ & 0.561 \\
\hline $\begin{array}{l}\text { Surgery start time in } \\
24 \text { hours }[B]\end{array}$ & $10: 29: 16 \pm 0: 36: 47$ & $10: 28: 42 \pm 0: 33: 46$ & $10: 29: 45 \pm 0: 39: 46$ & $\mathrm{t}(58)=-0.108$ & $-0: 20: 15$ to $0: 18: 11$ & 0.914 \\
\hline Latency in hours [B-A] & $0: 04: 14 \pm 0: 02: 20$ & $0: 04: 21 \pm 0: 02: 13$ & 0:04:09 $\pm 0: 02: 27$ & $\mathrm{t}(58)=0.330$ & $-0: 01: 01$ to $0: 01: 25$ & 0.742 \\
\hline $\begin{array}{l}\text { Surgery end time in } \\
24 \text { hours [C] }\end{array}$ & $11: 07: 12 \pm 0: 44: 40$ & $11: 08: 12 \pm 0: 45: 46$ & $11: 06: 18 \pm 0: 44: 24$ & $\mathrm{t}(58)=0.163$ & $-0: 21: 26$ to $0: 25: 14$ & 0.871 \\
\hline $\begin{array}{l}\text { Operative time in hours } \\
\text { [C-B] }\end{array}$ & $0: 37: 56 \pm 0: 16: 01$ & $0: 39: 30 \pm 0: 17: 57$ & $0: 36: 33 \pm 0: 14: 17$ & $\mathrm{t}(58)=0.694$ & $-0: 05: 33$ to $0: 11: 25$ & 0.484 \\
\hline $\begin{array}{l}\text { Exact time } 1 \text { st analgesic } \\
\text { taken after surgery in } \\
24 \text { hours }[D]^{1}\end{array}$ & $13: 29: 29 \pm 1: 14: 26$ & $12: 22: 55 \pm 0: 35: 23$ & $14: 27: 43 \pm 0: 44: 13$ & $\mathrm{t}(58)=-11.95$ & $-2: 25: 41$ to $-1: 43: 53$ & $0.001 *$ \\
\hline $\begin{array}{l}\text { Duration of analgesia in } \\
\text { hours [D-A] }\end{array}$ & $3: 04: 28 \pm 1: 08: 57$ & $1: 58: 34 \pm 0: 24: 52$ & $4: 02: 07 \pm 0: 34: 01$ & $\mathrm{t}(58)=-15.85$ & $-2: 18: 50$ to $-1: 48: 15$ & $0.001 *$ \\
\hline $\begin{array}{l}\text { Total No. of analgesics } \\
\text { consumed }\end{array}$ & $5.98 \pm 2.26$ & $8.04 \pm 1.52$ & $4.19 \pm 0.78$ & $\mathrm{t}(58)=12.51$ & 3.23 to 4.46 & $0.017 *$ \\
\hline
\end{tabular}

(LA: local anaesthetic, ADN: adrenaline, DXN: dexamethasone, CI: confidence interval)

${ }^{1}$ Reversal of nerve block.

$* P \leq 0.05$ is statistically significant.

Values are presented as mean \pm standard deviation.

Saroj Prasad Deo et al: Effectiveness of dexamethasone or adrenaline with lignocaine $2 \%$ for prolonging inferior alveolar nerve block: a randomized controlled trial. J Korean Assoc Oral Maxillofac Surg 2022 


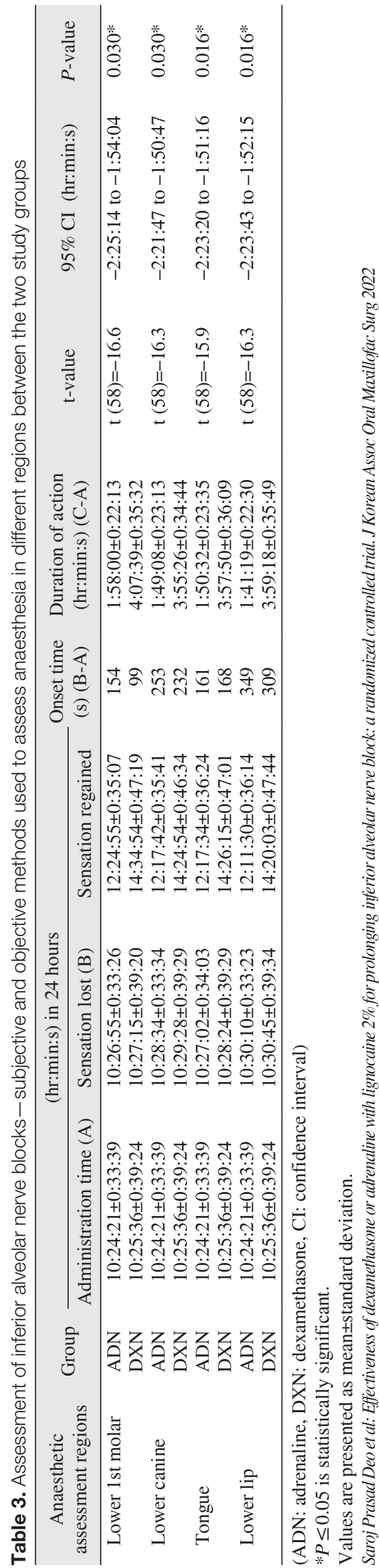

ing order at the molar $>$ tongue $>$ canine $>$ lip in both groups. (Fig. 2. B) Similarly, the time at which the first analgesic was consumed and the total number of NSAIDs needed to provide rescue postoperative analgesia were statistically significant between the study groups.(Table 2) The mean VAS was significant between the study groups at the $2 \mathrm{nd}, 4 \mathrm{th}, 5 \mathrm{th}, 6 \mathrm{th}$, 12th, 15th, 18th, and 21st hours as shown in Fig. 3.

\section{Benefits versus risks}

As shown in Fig. 4, the hemodynamic status including systolic and diastolic blood pressure, pulse rate, respiratory rate and $\mathrm{SPO}_{2}$ at preoperative, intraoperative, postoperative period after injection showed insignificant differences between the study groups. Postoperative sequelae such as facial oedema, trismus, and pain were observed after every TMS up to the first week postoperatively, but only facial oedema on the 2 nd postoperative day was significantly different between the groups. However, the overall measurements were greater in ADN compared to DXN.(Fig. 5) In addition, adverse drug effects were nonsignificant up to the first postoperative week, but intraoperative bleeding was significantly more frequent and nausea and vomiting significantly less frequent in DXN compared to ADN.(Table 4).

\section{Discussion}

This study compared the efficacy of dexamethasone over adrenaline adjuvants with lignocaine $2 \%$ in IANB. Past studies used dexamethasone adjuvants in long- to intermediateacting LAa and found significantly prolonged duration of action in brachial and femoral nerve blocks ${ }^{19-26}$. Although TMS has been most frequently used for postoperative acute pain studies ${ }^{9-13}$, there have not been many investigations conducted to determine the effectiveness of dexamethasone adjuvants with lignocaine in IANB. To the best of our knowledge, this study could be the first to use dexamethasone adjuvants with lignocaine in TMS. The null hypothesis was that the mean duration of action of DXN $(\mu 1)$ would be equal to that of ADN $(\mu 2)[H 0, \mu 1=\mu 2]$. Nevertheless, the present study results did not reveal the same mean duration of action in the two study groups. We found a significant difference in the duration of action between the study groups at molar teeth ( $P=0.030)$, canine teeth $(P=0.030)$, tongue $(P=0.016)$, and lip regions $(P=0.016)$ through use of independent Student's $t$ test, Levene's test, and $t$-test for equality.(Table 3) Therefore, we rejected the null hypothesis, and an alternative hypothesis 
A

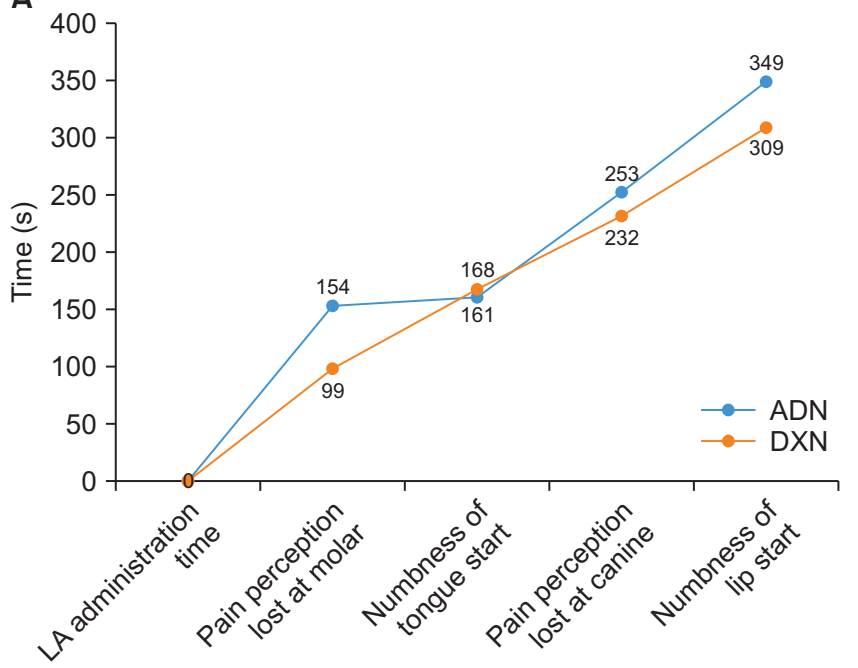

B

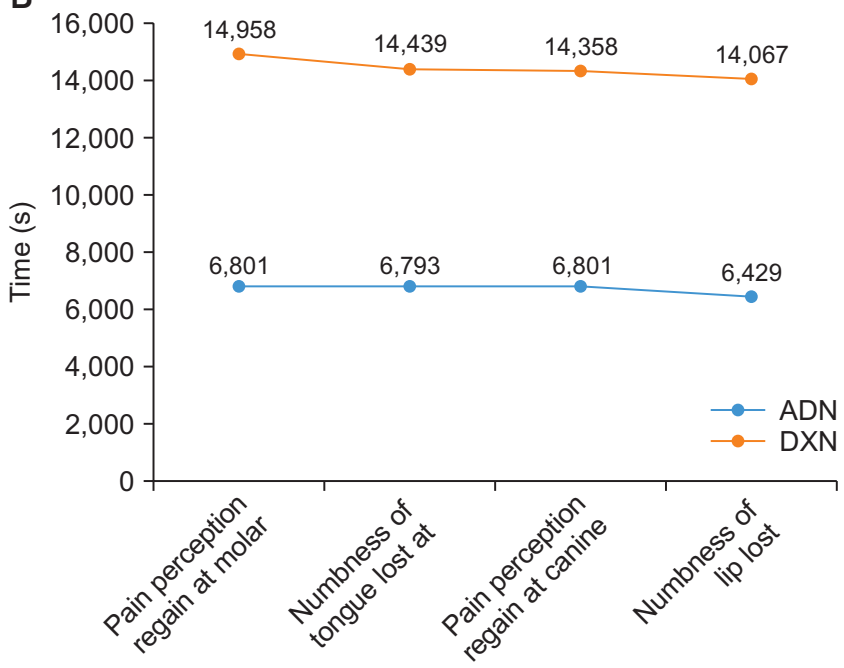

Fig. 2. A. Onset time of anaesthesia; subjective and objective assessment of pain by asking the patient felling lip and tongue numbness and pain perception of palpating with blunt instrument at different regions between groups. B. Duration of inferior alveolar nerve block (IANB); subjective and objective assessment of pain by asking the patient loss of lip and tongue numbness and regain of pain perception of palpating with blunt instrument at different regions between groups. (ADN: adrenaline, DXN: dexamethasone)

Saroj Prasad Deo et al: Effectiveness of dexamethasone or adrenaline with lignocaine $2 \%$ for prolonging inferior alveolar nerve block: a randomized controlled trial. J Korean Assoc Oral Maxillofac Surg 2022

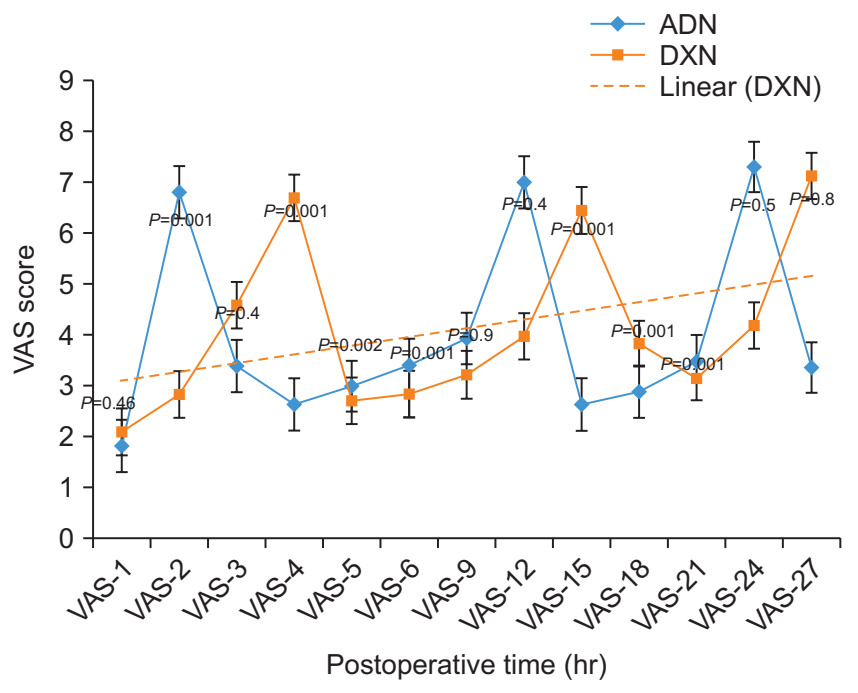

Fig. 3. Mean visual analogue scale (VAS) response with standard deviation of first 27 hours after third molar surgery. $P \leq 0.05$ is the statistically significant. 1st hour profound anesthesia in both groups. VAS is slightly rising up to 4 hours due to prolongation of IANB in dexamethasone (DXN). (ADN: adrenaline)

Saroj Prasad Deo et al: Effectiveness of dexamethasone or adrenaline with lignocaine $2 \%$ for prolonging inferior alveolar nerve block: a randomized controlled trial. J Korean Assoc Oral Maxillofac Surg 2022

(H1) was formed that the mean duration of analgesia should not be equal between the study groups $[\mathrm{H} 1, \mu 1 \neq \mu 2]$. Similarly, this study found a significant difference in the mean duration of perioperative analgesia between the two study groups $(\mathrm{t}$ $(58)=-15.85 ; 95 \%$ CI, $-2: 18: 50$ to $-1: 48: 15 ; P=0.001$ ). (Table 2) A meta-analysis by Choi et al..$^{34}$ found prolongation of

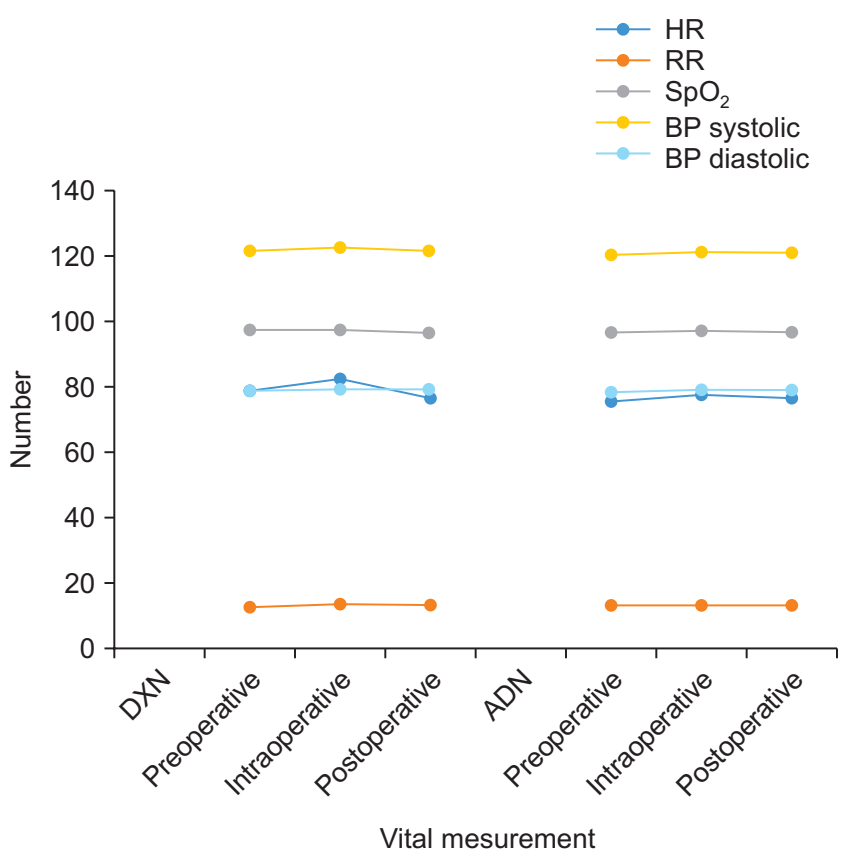

Fig. 4. Hemodynamic change after injection; intraoperative and postoperative vitals were statistically same with preoperative vitals in both groups. (DXN: dexamethasone, ADN: adrenaline, HR: heart rate, RR: respiratory rate, BP: blood pressure)

Saroj Prasad Deo et al: Effectiveness of dexamethasone or adrenaline with lignocaine $2 \%$ for prolonging inferior alveolar nerve block: a randomized controlled trial. J Korean Assoc Oral Maxillofac Surg 2022

nerve block duration to be in the range from 168 to $343 \mathrm{~min}$ utes (mean, 175 minutes; 95\% CI, 73 to 277) with intermediate-acting LAa. Accurate comparison with the above studies 
is not justified because the present study used dexamethasone adjuvants in the trigeminal nerve branches, i.e., IAN for TMS is composed of only small, rapid-firing sensory fibres. However, the above studies used dexamethasone in larger diameter a-delta fibres. Smaller fibres are generally more susceptible to LAa because a given volume of LA solution can more readily block the requisite number of sodium channels for impulse transmission to be entirely interrupted. Moreover, several previous studies had reported a statistically significant increase in the mean duration of soft tissue anaesthesia ranging from 197 to 301 minutes $(P \leq 0.05)$ when dexamethasone was administered locally into the pterygomandibular space

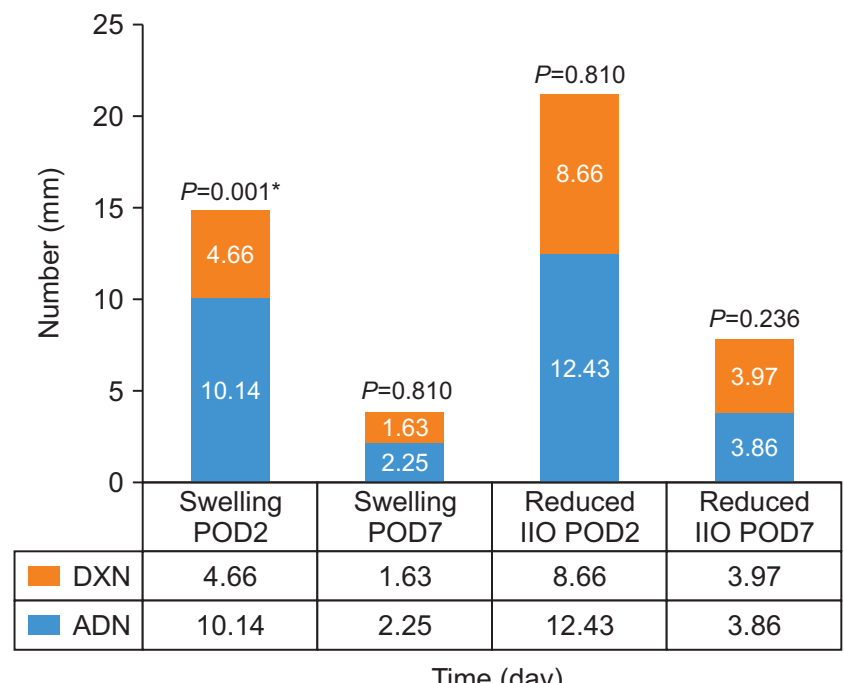

Time (day)

Fig. 5. Postoperative recovery from third molar surgery sequalae; left side, 2 nd and 7 th day reduction of facial contour from baseline in $\mathrm{mm}$ and right side, 2 nd and 7 th day reduced $\mathrm{IO}$ from normal mouth opening in $\mathrm{mm}$. Postoperative swelling was statistically significantly reduced in 2nd postoperative day in dexamethasone (DXN). ${ }^{*} P \leq 0.05$ is statistically significant. (ADN: adrenaline, POD: postoperative day)

Saroj Prasad Deo et al: Effectiveness of dexamethasone or adrenaline with lignocaine $2 \%$ for prolonging inferior alveolar nerve block: a randomized controlled trial. J Korean Assoc Oral Maxillofac Surg 2022 after IANB with lignocaine $2 \%$ with adrenaline ${ }^{10,35}$. Unfortunately, those studies did not assess perioperative analgesia and VAS and were not well-documented. To the best of our knowledge, the current study could be the first that used coadmix dexamethasone adjuvants with short-acting LAa, i.e., lignocaine $2 \%$. Therefore, this is a unique study because of its design, drugs, volume, and assessment tools compared to previous studies. Nevertheless, this study used singleinjection techniques, offering many advantages over dualinjection techniques used in previous studies.

The present study compared the anaesthetic properties of study drugs through both subjective (patient perspective) and objective assessment methods. The patient perspective, i.e., VAS and total number of NSAIDs consumed for rescue postoperative analgesia, depended on the patient's decision about the level of pain. Objective assessment by pricking the first molar, canine teeth, lower lip, and tongue every $20 \mathrm{~min}$ utes was used until normal sensation was regained. We found immediate postoperative VAS, i.e., VAS-2, VAS-4, VAS-5, VAS-6, VAS-12, VAS-15, VAS-18, and VAS-21, to exhibit statistically significant differences between the study groups. (Fig. 3) Similarly, past studies found a significant reduction in VAS in the early postoperative hours ${ }^{19-25}$. Fig. 3 shows the step ladder pattern of VAS in both study groups. The first step in the graph is due to reversal of the anaesthetic effect of the study drugs. A significant difference between the study groups was shown at hour 2 for ADN and at hour 4 for DXN.(Fig. 3) These anaesthetic properties of the study drugs are considered the duration of action. The 2nd and 3rd steps in the VAS graph could be due to clearance of the NSAIDs ${ }^{36}$. VAS-4 and VAS-15 were lower in ADN and was statistically significant between the study groups. The step-in graph could have occurred by inhibiting $\beta$-endorphins from entering the anterior pituitary by dexamethasone, which might have increased pain $^{37}$. The systemic anti-inflammatory effect of dexametha-

Table 4. Adverse outcomes found between the study groups

\begin{tabular}{lcccc}
\hline \multicolumn{1}{c}{ Characteristic } & Overall $(\mathrm{n}=60)$ & Group ADN $(\mathrm{n}=28)$ & Group DXN $(\mathrm{n}=32)$ & $P$-value \\
\hline Intraoperative bleeding & $17(28.3)$ & $3(10.7)$ & $14(43.8)$ & $0.001^{*}$ \\
Slow wound healing & $9(15.0)$ & $3(10.7)$ & $6(18.8)$ & 0.482 \\
Bruise & $11(18.3)$ & $7(25.0)$ & $4(12.5)$ & 0.318 \\
Paraesthesia/nerve palsy & $1(1.7)$ & $1(3.6)$ & $0(0)$ & 0.475 \\
Nausea and vomiting & $16(26.7)$ & $14(50.0)$ & $2(6.3)$ & $0.001^{*}$ \\
Mood changes & $4(6.7)$ & $0(0)$ & $4(12.5)$ & 0.116 \\
Wound infection & $5(8.3)$ & $2(7.1)$ & $3(9.4)$ & $>0.999$ \\
\hline
\end{tabular}

(ADN: adrenaline, DXN: dexamethasone, CI: confidence interval)

$* P \leq 0.05$ is statistically significant.

Values are presented as number (\%).

Saroj Prasad Deo et al: Effectiveness of dexamethasone or adrenaline with lignocaine 2\% for prolonging inferior alveolar nerve block: a randomized controlled trial. J Korean Assoc Oral Maxillofac Surg 2022 
sone could probably be the reason for statistically significant VAS-12, VAS-18, and VAS-21 between the two study groups. Furthermore, the prolonged durations of action in DXN were confirmed at 2 hours for ADN and 4 hours for DXN (t $(58)=-11.95 ; 95 \% \mathrm{CI},-2: 25: 41$ to $-1: 43: 53 ; P=0.001)$. Again, we found that DXN patients consumed a smaller number of NSAIDs. Therefore, NSAID-associated adverse drug reactions could be minimized using single-dose dexamethasone.

Subjective and objective anaesthesia assessments in different regions ${ }^{38}$ (first molar, canine, lip, and tongue) represented loss and regain of normal sensation.(Table 3) Onset time is the latency period between LA administration to the beginning of numbness/loss of sensation. The duration of action is the beginning of numbness/loss of sensation to the return of sensation. The onset of numbness first began at the first molar, then tongue, canine, and finally the lip.(Fig. 2. A) In comparison between the study groups, onset time was not statistically significant. However, DXN exhibited an earlier onset time compared to ADN, possibly because of dexamethasone fastening the diffusion of the LA solution into the nerve sheath. The duration of action in all four regions was statistically significant between the study groups.(Table 3) As patients recovered from anaesthesia, they first regained sensation at the lip, then the tongue, and finally at the canine and first molar.(Fig. 2. B)

In Fig. 2, onset time and duration of action exhibited reverse patterns. Clinicians, especially dentists who perform IANBs, should be aware of these differential onset times and durations of action at different regions. This phenomenon could occur because the trigeminal nerve branches are composed of only tiny, rapid-firing sensory fibres. The neuroanatomy of IAN fibres has been described in anatomy textbooks, where a nerve encloses a cable-like bundle of axons (neurons) called fibres, surrounded by endoneurium. The axons are bundled together into groups called fascicles. The perineurium wraps each fascicle, and the entire nerve is wrapped with epineurium.(Fig. 6) The fibres near the surface of the nerve are called mental fibres and tend to innervate more proximal regions, i.e., the molar area, whereas fibres in the centre are called core bundles and innervate the more distal regions, i.e., incisors and canines. LA solution deposited onto the surface of the nerve sheath slowly diffuses from the mental fibres to the core fibres of IAN over time. Early diffusion into the mental fibres provided early onset in the molar region (99 seconds vs 154 seconds), and late diffusion into the core fibres resulted in delayed onset time (309 seconds vs 349 seconds) between DXN and ADN. Similarly, the lowest duration of block (6,429 seconds vs 14,067 seconds) and longest onset time (309 seconds vs 349 seconds) were observed in the lip between DXN and ADN.(Fig. 2) Therefore, reversal of local analgesia occurs in an inverse manner to onset. LA solution in mental fibres washes out earlier than that in core fibres, which is the probable mechanism by which we found the highest nerve block duration in the molar region and the lowest in the lip region. As a result, the lipid-binding capacity of dexamethasone could delay the recovery of local anaesthesia, leading to prolongation of nerve blocks in $\mathrm{DXN}^{39}$.

Presently, there is no literature predicting the interaction of dexamethasone with lignocaine in vivo or in vitro. However, the safety profile of dexamethasone's perineural use is wellestablished, and no trial has reported neurotoxicity attributable to dexamethasone. In this study, patients were hemodynamically stable in both study groups when we recorded vitals up to 6 hours postoperatively.(Fig. 4) Pain, trismus, and facial swelling are the most common postoperative sequelae after TMS and have been described frequently in the literature. These are an effect of local inflammatory mediator release immediately after surgical trauma ${ }^{40,41}$. In this study, postoperative recovery in the 2 nd postoperative day exhibited significantly reduced swelling and perioperative analgesia in DXN compared with ADN.(Fig. 5) Similarly, many past studies found significant recovery of postoperative sequelae after TMS with administration of a single dose of dexamethasone

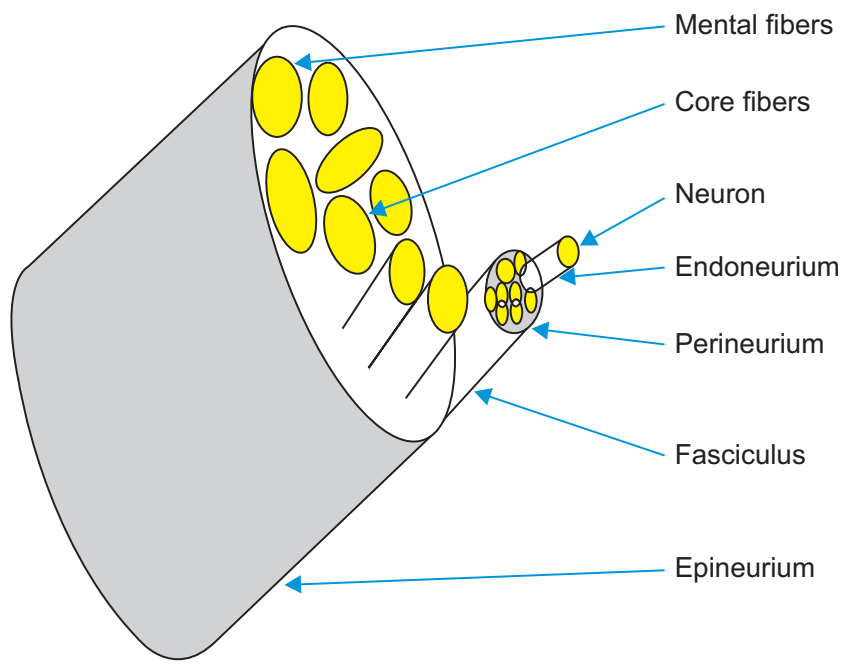

Fig. 6. Neuro-anatomy of inferior alveolar nerve; cable wire network of neurons surrounds by the endoneurium in central (core) and periphery (mental) fibers, wrapped into the perineurium and epineurium diffusion of local anaesthetic solution from the mantle to core fibers.

Saroj Prasad Deo et al: Effectiveness of dexamethasone or adrenaline with lignocaine $2 \%$ for prolonging inferior alveolar nerve block: a randomized controlled trial. J Korean Assoc Oral Maxillofac Surg 2022 
through different routes, i.e., per-oral, intravenous, intramuscular, local (intra-alveolar or submucosal), and perineural. Therefore, the anti-inflammatory action of dexamethasone is the primary mechanism of action for the reduction of these sequelae on the second postoperative day. As a result, this finding has improved the immediate postoperative quality of life of patients. Other adverse outcomes such as slow wound healing, bruising, paraesthesia of the lip, mood changes, and wound infection were studied for one week after TMS and were not statistically significant between the study groups. However, intraoperative bleeding was significantly more frequent in $\mathrm{ADN}$ and nausea and vomiting significantly less frequent in DXN.(Table 4)

Intraoperative bleeding could be a disadvantage of using dexamethasone. This injection technique has offered many advantages over the dual-injection technique of dexamethasone, such as one short injection, better patient compliance, exact anatomical deposition, and fast onset time resulting in improved success rates. The benefit is that this technique allows for patients to return to work earlier, avoid hospital admissions, and reduces postoperative morbidity after TMS. Dexamethasone adjuvants could be used in conditions like hypertension, cardiovascular disease, and hyperthyroid disease. Unfortunately, the use of dexamethasone is discouraged in patients on anti-depressant medications where adrenaline is contraindicated. In addition, dexamethasone should not be used in patients with diabetes mellitus, peptic ulcers, renal insufficiencies, and in pregnant women or lactating females. A limitation to the present study is the lack of assessment of the depth of anaesthesia and the inability to perform triple blinding. More studies are required to evaluate perineural dexamethasone's practical benefits and clinical safety as an LA adjunct in IANB.

\section{Conclusion}

Single-injection techniques have produced profound perioperative analgesia using adjuvant dexamethasone with lignocaine, which prolongs the duration of IANBs. An additional benefit of adjuvant dexamethasone with lignocaine was an improvement in postoperative sequelae such as trismus, swelling, nausea, vomiting, and perioperative analgesia. Therefore, a simple one-step single injection technique improves the overall surgical outcome and the patient's postoperative quality of life. Therefore, we recommend dexamethasone for all routine third molar surgeries except where it is contraindicated.

\section{ORCID}

Saroj Prasad Deo, https://orcid.org/0000-0001-5286-2065

Md Shakeel Ahmad, https://orcid.org/0000-0001-8082-5210

Abanish Singh, https://orcid.org/0000-0001-5659-9807

\section{Authors' Contributions}

All authors contributed to the study's conception and design. S.P.D. was involved in all the study steps, i.e., proposal writing and ethical approval; collection and interpretation of data; and drafting of the manuscript, tables, and figures. All authors commented on the previous versions of the manuscript. A.S. and M.S.A. performed interpretation of data, drafting, and reviews of the manuscript. Finally, all authors read and approved the final manuscript.

\section{Acknowledgements}

The trial drugs and armamentariums were provided by the Oral \& Maxillofacial Surgery Department of Tribhuvan University, Nepal.

The authors thank all the participants for their voluntary participation in this study. We acknowledge Mr. Dharanidhar Baral and Mrs. Rachana Deo for their contribution to statistical analysis and language editing, respectively.

\section{Ethics Approval and Consent to Participate}

This study followed the Guidelines for Institutional Review Committees (IRCs) for Health Research in Nepal under the Helsinki Declaration (2013). The study proposal was submitted to the Institutional Review Committee of the National Medical College, Birganj, Nepal, Tribhuvan University, and this study was conducted under the approval of the IRC (No. F-NMC/422/075/076). Written informed consent was obtained from all the patients before participation in this study. Eligible participants in this study were volunteers and were not compensated.

\section{Conflict of Interest}

No potential conflict of interest relevant to this article was reported. 


\section{References}

1. Calatayud J, González A. History of the development and evolution of local anesthesia since the coca leaf. Anesthesiology 2003;98:1503-8. https://doi.org/10.1097/00000542-20030600000031

2. Ogle OE, Mahjoubi G. Advances in local anesthesia in dentistry. Dent Clin North Am 2011;55:481-99, viii. https://doi.org/10.1016/ j.cden.2011.02.007

3. Albaladejo P, Aubrun F, Samama CM, Jouffroy L, Beaussier M, Benhamou $\mathrm{D}$, et al. The structure, organisation and perioperative management of ambulatory surgery and anaesthesia in France: methodology of the SFAR-OPERA study. Anaesth Crit Care Pain Med 2017;36:307-12. https://doi.org/10.1016/j.accpm.2016.10.002

4. Yagiela JA. Recent developments in local anesthesia and oral sedation. Compend Contin Educ Dent 2004;25:697-706; quiz 708.

5. Chew ST, Tan T, Tan SS, Ip-Yam PC. A survey of patients' knowledge of anaesthesia and perioperative care. Singapore Med J 1998; 39:399-402.

6. Buvanendran A, Fiala J, Patel KA, Golden AD, Moric M, Kroin JS. The incidence and severity of postoperative pain following inpatient surgery. Pain Med 2015;16:2277-83. https://doi.org/10.1111/ pme. 12751

7. Gan TJ, Habib AS, Miller TE, White W, Apfelbaum JL. Incidence, patient satisfaction, and perceptions of post-surgical pain: results from a US national survey. Curr Med Res Opin 2014;30:149-60. https://doi.org/10.1185/03007995.2013.860019

8. Meissner W, Coluzzi F, Fletcher D, Huygen F, Morlion B, Neugebauer E, et al. Improving the management of post-operative acute pain: priorities for change. Curr Med Res Opin 2015;31:2131-43. https://doi.org/10.1185/03007995.2015.1092122

9. Deo SP. Effect of submucosal injection of dexamethasone on postoperative sequelae of third molar surgery. JNMA J Nepal Med Assoc 2011;51:72-8.

10. Deo SP. Role of addition of dexamethasone to lignocaine $2 \%$ with adrenaline in dental nerve blocks for third molar surgery: a prospective randomized control trial. Ann Maxillofac Surg 2016;6: 260-6. https://doi.org/10.4103/2231-0746.200341

11. Latt MM, Kiattavorncharoen S, Boonsiriseth K, Pairuchvej V, Wongsirichat $\mathrm{N}$. The efficacy of dexamethasone injection on postoperative pain in lower third molar surgery. J Dent Anesth Pain Med 2016;16:95-102. https://doi.org/10.17245/jdapm.2016.16.2.95

12. Barden J, Edwards JE, McQuay HJ, Andrew Moore R. Pain and analgesic response after third molar extraction and other postsurgical pain. Pain 2004;107:86-90. https://doi.org/10.1016/ j.pain.2003.09.021

13. Marković AB, Todorović L. Postoperative analgesia after lower third molar surgery: contribution of the use of long-acting local anesthetics, low-power laser, and diclofenac. Oral Surg Oral Med Oral Pathol Oral Radiol Endod 2006;102:e4-8. https://doi. org/10.1016/j.tripleo.2006.02.024

14. Danielsson K, Evers H, Holmlund A, Kjellman O, Nordenram A, Persson NE. Long-acting local anaesthetics in oral surgery. Clinical evaluation of bupivacaine and etidocaine for mandibular nerve block. Int J Oral Maxillofac Surg 1986;15:119-26. https://doi. org/10.1016/s0300-9785(86)80131-4

15. Crincoli V, Favia G, LImongelli L, Tempesta A, Brienza N. The effectiveness of ropivacaine and mepivacaine in the postoperative pain after third lower molar surgery. Int J Med Sci 2015;12:862-6. https://doi.org/10.7150/ijms.13072

16. Prabhakar A, Lambert T, Kaye RJ, Gaignard SM, Ragusa J, Wheat $\mathrm{S}$, et al. Adjuvants in clinical regional anesthesia practice: a comprehensive review. Best Pract Res Clin Anaesthesiol 2019;33:41523. https://doi.org/10.1016/j.bpa.2019.06.001

17. Renck H, Hassan HG. Epinephrine as an adjuvant to amino-amide local anesthetics does not prolong their duration of action in infra- orbital nerve block in the rat. Acta Anaesthesiol Scand 1992;36: 387-92. https://doi.org/10.1111/j.1399-6576.1992.tb03486.x

18. Marhofer P, Columb M, Hopkins PM, Greher M, Marhofer D, Bienzle M, et al. Dexamethasone as an adjuvant for peripheral nerve blockade: a randomised, triple-blinded crossover study in volunteers. Br J Anaesth 2019;122:525-31. https://doi.org/10.1016/ j.bja.2019.01.004

19. Swami SS, Keniya VM, Ladi SD, Rao R. Comparison of dexmedetomidine and clonidine ( $\alpha 2$ agonist drugs) as an adjuvant to local anaesthesia in supraclavicular brachial plexus block: a randomised double-blind prospective study. Indian J Anaesth 2012;56:243-9. https://doi.org/10.4103/0019-5049.98767

20. Zhang C, Li C, Pirrone M, Sun L, Mi W. Comparison of dexmedetomidine and clonidine as adjuvants to local anesthetics for intrathecal anesthesia: a meta-analysis of randomized controlled trials. J Clin Pharmacol 2016;56:827-34. https://doi.org/10.1002/jcph.666

21. McCartney CJ, Duggan E, Apatu E. Should we add clonidine to local anesthetic for peripheral nerve blockade? A qualitative systematic review of the literature. Reg Anesth Pain Med 2007;32:330-8. https://doi.org/10.1016/j.rapm.2007.02.010

22. Bharti N, Sardana DK, Bala I. The analgesic efficacy of dexmedetomidine as an adjunct to local anesthetics in supraclavicular brachial plexus block: a randomized controlled trial. Anesth Analg 2015;121: 1655-60. https://doi.org/10.1213/ANE.0000000000001006

23. Candido KD, Winnie AP, Ghaleb AH, Fattouh MW, Franco CD. Buprenorphine added to the local anesthetic for axillary brachial plexus block prolongs postoperative analgesia. Reg Anesth Pain Med 2002;27:162-7. https://doi.org/10.1053/rapm.2002.30671

24. Shah A, Halli R, Merchant Y, Kshirsagar R, Khurana J. Efficacy of ketamine as an adjunct to local anesthesia in the surgical removal of impacted mandibular third molars - a split mouth prospective controlled clinical study. J Clin Diagn Res 2016;10:ZC29-33. https://doi.org/10.7860/JCDR/2016/19677.8638

25. Ettinger KS, Jacob AK, Viozzi CF, Van Ess JM, Fillmore WJ, Arce K. Does intravenous midazolam dose influence the duration of recovery room stay following outpatient third molar surgery? J Oral Maxillofac Surg 2015;73:2287-93. https://doi.org/10.1016/ j.joms.2015.06.164

26. Tempestini Horliana AC, de Brito MA, Perez FE, Simonetti MP, Rocha RG, Borsatti MA. Hyaluronidase increases the duration of mepivacaine in inferior alveolar nerve blocks. J Oral Maxillofac Surg 2008;66:286-90. https://doi.org/10.1016/j.joms.2007.06.628

27. Yadav RK, Sah BP, Kumar P, Singh SN. Effectiveness of addition of neostigmine or dexamethasone to local anaesthetic in providing perioperative analgesia for brachial plexus block: a prospective, randomized, double blinded, controlled study. Kathmandu Univ Med J (KUMJ) 2008;6:302-9. https://doi.org/10.3126/kumj. v6i3.1704

28. Shah DM, Arora M, Trikha A, Prasad G, Sunder R, Kotwal P, et al. Comparison of dexamethasone and clonidine as an adjuvant to $1.5 \%$ lignocaine with adrenaline in infraclavicular brachial plexus block for upper limb surgeries. J Anaesthesiol Clin Pharmacol 2015;31: 354-9. https://doi.org/10.4103/0970-9185.161672

29. Biradar PA, Kaimar P, Gopalakrishna K. Effect of dexamethasone added to lidocaine in supraclavicular brachial plexus block: a prospective, randomised, double-blind study. Indian J Anaesth 2013; 57:180-4. https://doi.org/10.4103/0019-5049.111850

30. Alzeftawy AE, El Morad MB. Dexamethasone compared to dexmedetomidine as an adjuvant to local anesthetic mixture in peribulbar block for vitreoretinal surgery. A prospective randomized study. Anesth Essays Res 2018;12:359-65. https://doi.org/10.4103/aer. AER 22417

31. Vadhanan P, Ganesh N, Ahmed MIH. Comparison of dexamethasone and buprenorphine as adjuvant in ultrasound-guided brachial plexus blocks: a randomized controlled trial. Anesth Essays Res 2018;12:176-9. https://doi.org/10.4103/aer.AER_129_17

32. Kheirabadi D, Shafa A, Hirmanpour A, Zareh F. Prophylactic ef- 
fects of intravenous dexamethasone and lidocaine on attenuating hemodynamic-respiratory and pain complications in children undergoing cleft palate repair surgery with general anesthesia. J Pain Palliat Care Pharmacother 2020;34:63-8. https://doi.org/10.1080/1 5360288.2019.1706691

33. McHardy PG, Singer O, Awad IT, Safa B, Henry PDG, Kiss A, et al. Comparison of the effects of perineural or intravenous dexamethasone on low volume interscalene brachial plexus block: a randomised equivalence trial. Br J Anaesth 2020;124:84-91. https:// doi.org/10.1016/j.bja.2019.08.025

34. Choi S, Rodseth R, McCartney CJ. Effects of dexamethasone as a local anaesthetic adjuvant for brachial plexus block: a systematic review and meta-analysis of randomized trials. Br J Anaesth 2014; 112:427-39. https://doi.org/10.1093/bja/aet417

35. Bhargava D, Sreekumar K, Rastogi S, Deshpande A, Chakravorty N. A prospective randomized double-blind study to assess the latency and efficacy of twin-mix and 2\% lignocaine with 1:200,000 epinephrine in surgical removal of impacted mandibular third molars: a pilot study. Oral Maxillofac Surg 2013;17:275-80. https:// doi.org/10.1007/s10006-012-0372-3

36. Calvo AM, Santos GM, Dionísio TJ, Marques MP, Brozoski DT, Lanchote VL, et al. Quantification of piroxicam and 5'-hydroxypiroxicam in human plasma and saliva using liquid chromatography-tandem mass spectrometry following oral administration. J Pharm Biomed Anal 2016;120:212-20. https://doi.org/10.1016/ j.jpba.2015.12.042

37. Hargreaves KM, Schmidt EA, Mueller GP, Dionne RA. Dexamethasone alters plasma levels of beta-endorphin and postoperative pain. Clin Pharmacol Ther 1987;42:601-7. https://doi.org/10.1038/ clpt.1987.206

38. Hosgor H, Coskunses FM, Tokuc B. Correlation between preoperative pressure pain assessments and anxiety and postoperative pain in impacted lower third molar surgery. J Korean Assoc Oral Maxillofac Surg 2021;47:15-9. https://doi.org/10.5125/jkaoms.2021.47.1.15

39. Benzon HT, Chew TL, McCarthy RJ, Benzon HA, Walega DR. Comparison of the particle sizes of different steroids and the effect of dilution: a review of the relative neurotoxicities of the steroids. Anesthesiology 2007;106:331-8. https://doi. org/10.1097/00000542-200702000-00022

40. Alexander RE, Throndson RR. A review of perioperative corticosteroid use in dentoalveolar surgery. Oral Surg Oral Med Oral Pathol Oral Radiol Endod 2000;90:406-15. https://doi.org/10.1067/ moe. 2000.109778

41. Markiewicz MR, Brady MF, Ding EL, Dodson TB. Corticosteroids reduce postoperative morbidity after third molar surgery: a systematic review and meta-analysis. J Oral Maxillofac Surg 2008;66: 1881-94. https://doi.org/10.1016/j.joms.2008.04.022

How to cite this article: Deo SP, Ahmad MS, Singh A. Effectiveness of dexamethasone or adrenaline with lignocaine $2 \%$ for prolonging inferior alveolar nerve block: a randomized controlled trial. J Korean Assoc Oral Maxillofac Surg 2022;48:21-32. https://doi. org/10.5125/jkaoms.2022.48.1.21 